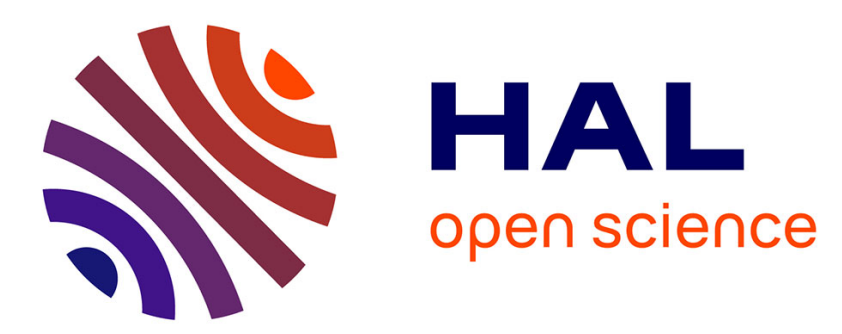

\title{
Pedestrian fatality and impact speed squared: Cloglog modeling from French national data
}

\author{
Jean-Louis Martin, Dan Wu
}

\section{To cite this version:}

Jean-Louis Martin, Dan Wu. Pedestrian fatality and impact speed squared: Cloglog modeling from French national data. Traffic Injury Prevention, 2017, 10.1080/15389588.2017.1332408 . hal01557978

\section{HAL Id: hal-01557978 \\ https://hal.science/hal-01557978}

Submitted on 6 Jul 2017

HAL is a multi-disciplinary open access archive for the deposit and dissemination of scientific research documents, whether they are published or not. The documents may come from teaching and research institutions in France or abroad, or from public or private research centers.
L'archive ouverte pluridisciplinaire HAL, est destinée au dépôt et à la diffusion de documents scientifiques de niveau recherche, publiés ou non, émanant des établissements d'enseignement et de recherche français ou étrangers, des laboratoires publics ou privés. 
Pedestrian fatality and impact speed squared: cloglog modeling from French national data

Authors

Jean-Louis Martin ${ }^{\text {a }}$

Dan $\mathrm{Wu}^{\mathrm{a}}$

a: Univ Lyon, Université Lyon 1, IFSTTAR, UMRESTTE UMR_T 9405, F-69675, LYON, France

Corresponding author:

Jean-Louis Martin

IFSTTAR/UMRESTTE, 25 Avenue François Mitterrand, 69675 Bron Cedex, France

Tel.: +33 4721425 12; fax: +33 472142520

E-mail: jean-louis.martin@ifsttar.fr 


\section{Abstract}

Objective: The present study estimates pedestrians' risk of death according to the impact speed when hit by a passenger car in a frontal collision.

Methods: Data were coded for all fatal crashes in France in 2011 and for a random sample of 1/20 $0^{\text {th }}$ of all road injuries for the same year, and weighted to take account of police under-reporting of mild injury. A cloglog model was used to optimize risk adjustment for high collision speeds. The fit of the model on the data was also improved by using the square of the impact speed, which best matches the energy dissipated in the collision.

Results: Modeling clearly demonstrated that the risk of death was very close to 1 when impact speeds exceeded $80 \mathrm{~km} / \mathrm{h}$. For speeds less than $40 \mathrm{~km} / \mathrm{h}$, as data representative of all crashes resulting in injury were used, the estimated risk of death was fairly low. However, although the curve seemed deceptively flat below $50 \mathrm{~km} / \mathrm{h}$, the risk of death in fact rose 2-fold between 30 and $40 \mathrm{~km} / \mathrm{h}$ and 6-fold between 30 and $50 \mathrm{~km} / \mathrm{h}$. For any given speed, the risk of death was much higher for more elderly subjects, especially over 75 years of age. These results concern frontal crashes involving a passenger car. Collisions involving trucks are far less frequent, but half result in the pedestrian being run over, incurring greater mortality.

Conclusions: For impact speeds below $60 \mathrm{~km} / \mathrm{h}$, the shape of the curve relating probability of death to impact speed was very similar to those reported in recent rigorous studies. For higher impact speeds, the present model allows the curve to rise ever more steeply, giving a much better fit to observed data. The present results confirm that, when a pedestrian is struck by a car, impact speed is a major risk factor, thus providing a supplementary argument for strict speed limits in areas where pedestrians are highly exposed.

Key-words: crash; pedestrian; impact speed; fatality; statistical modeling 


\section{INTRODUCTION}

According to the most recent WHO report (WHO 2015), 22\% of road traffic deaths concern pedestrians, but the percentage varies greatly between continents: 39\% in Africa, 26\% in Europe, 22\% in the Americas, but 13\% in South-East Asia. This considerable difference corresponds to differences in exposure, travel often being on foot in certain countries. It also corresponds to differences in road-user behavior regarding safety, and especially motorists' consideration for pedestrians (or cyclists) with whom they need to share the road. In all countries, pedestrians injured in road crashes are mainly hit by motor vehicles, and most often by passenger cars (Alhajyaseen et al. 2013; Pulugurtha and Sambhara 2011; Richmond et al. 2014a; Richmond et al. 2014b). The interest of developing active and passive safety devices in cars is clear (Zegeer and Bushell 2012). In France in 2011, some 13\% of road crash fatalities concerned pedestrians (ONISR 2014), whereas pedestrians made up about $7 \%$ of road injuries as a whole.

Whatever the country and circumstances, the severity of pedestrian injury depends on 5 factors: (1) the energy dissipated in the collision, which is related to the speed of the vehicle at the moment of impact; (2) the shape and stiffness of the vehicle surfaces striking the impacted body areas; (3) the post-impact kinematics of the pedestrian's body; (4) possible impact against the ground or a secondary obstacle; and (5) the pedestrian's individual capacity to withstand the impact or impacts.

Several recent articles assessed the relation between pedestrians' risk of death and impact speed (Davis 2001; Hannawald and Kauer 2004; Rosen and Sander 2009; Tefft 2013).

Rosen (Rosen et al. 2011a) published a very interesting review of the literature on the importance of impact speed, selecting recent articles that were the most rigorous in terms of sampling and statistical methods, and based on real-world crashes. Regarding factor 2, studies of the influence of vehicle type (Ballesteros et al. 2004; Roudsari et al. 2004) or shape on resulting lesions were likewise based on real-world crash data (Crandall et al. 2002; Henary et al. 2003; Mallory et al. 2012; Martin et al. 2011; Otte 1999); there have also been studies using simulations, which have the advantage of being able to take body kinematics after impact into account (Crocetta et al. 2015; Gupta and Yang 2013; Han et al. 2012; Okamoto et al. 2003). Impact against the ground or secondary obstacles has been less studied, mainly due to lack of precise observations and the wide variety of possible obstacles (Badea-Romero and Lenard 2013). Finally, injury severity has often been studied as a function of age and gender, (Demetriades et al. 2004; Henary et al. 2006; Kim et al. 2008; Richards and Carroll 2012), but less often as a function of anthropometric data such as height (Watanabe et al. 2012) or body mass index (Tefft 2013).

The various published correlations between risk of death and impact speed all applied logistic curve modeling, which automatically applies symmetry around the inflection point with probability of 0.5, whereas there is in fact no reason why the curve slope should diminish after this point. Obviously, the probability of death must always lie between 0 and 1, but there are other modeling techniques which can also satisfy this condition. Furthermore, since the energy dissipated during the impact correlates with the kinetic energy of the vehicle just prior to impact, fitting the relationship in terms of the square of the impact speed seems most relevant. The present data are the first in France to provide an estimate of impact speed in a representative distribution of pedestrian crashes.

Pedestrian fatality and impact speed squared: Cloglog modeling from French national data, accepted author version, $\quad$ http://dx.doi.org/10.1080/15389588.2017.1332408 
After describing risk factors for fatality in crashes involving pedestrians and vehicles, the main objective of the study was to determine a fatality risk curve for pedestrians struck by a passenger car, drawing on representative data for road injury as a whole in France. Particular attention was paid to modeling and optimal data adjustment, including high vehicle speeds. The role of other factors for fatal outcome, such as pedestrian age and gender or the part of the vehicle involved, were also explored.

\section{METHODS}

The study database included crashes reported by the police, occurring on a highway or street open to the public, involving one or more vehicles, resulting in either one or more pedestrian deaths within 30 days of the crash (fatal crashes) or else no deaths within 30 days (non-fatal crashes involving injury). All such fatal crashes occurring in France in 2011 were included, plus a random sample of 1/20th of non-fatal crashes for the same year.

Data comprised: general crash characteristics, based on complete reading of the police report and associated documents describing the configuration of the crash (photographs, diagrams); the situation in which the crash occurred; human factors; road-user maneuvers in the moments leading up to the crash; and points of impact.

\section{Data Weighting and Underestimation in Police Data}

All fatal crashes in 2011 were included in the database. As the non-fatal crash data-set was a random 1/20 ${ }^{\text {th }}$ sample, a first weighting of 20 had to be applied. Secondly, the police are not in fact aware of all injuries and so cannot report them all systematically. These issues of underestimation and bias have been found in several countries (Elvik and Mysen 1999), and have been the subject of several studies by our team (Amoros et al. 2007; Amoros et al. 2006). Police underestimation depends particularly on the severity of the crash, presence of third parties, and type of road-user involved. To take it into account, correction coefficients were estimated following a method described elsewhere (Amoros et al. 2008), based on comparison, which is possible in the Rhône administrative Département, between the police data and those of the Rhône Road-Crash Registry, which inventories all road crash victims treated in all the health-care facilities within the area.

Correction coefficients were calculated using a capture-recapture method, then a projection method. These two steps have been validated assuming certain conditions (Hook and Regal 1995).

More specifically, the correction coefficients took account of crash severity (fatal or non-fatal), type of police authority (there being three different law enforcement authorities in France), type of road, presence of a third party, type of user involved (car user, motorized two-wheeler, cyclist, pedestrian, other), and injury severity (hospital admission or not).

Non-fatal injuries were thus weighted by multiplying these two weighting factors together: sample fraction, and correction coefficient for police underestimation bias. Using these weightings improved estimation of the probability of death, which would otherwise have been overestimated due to under-recording of non-fatal crashes by the police.

The estimators then took account of these weightings to obtain valid variances. In practice, calculation took account of weightings, using either SAS software version 9.4 (surveymeans, surveyfreq and surveylogistic procedures) or R (survey package).

Pedestrian fatality and impact speed squared: Cloglog modeling from French national data, accepted author version, $\quad$ http://dx.doi.org/10.1080/15389588.2017.1332408 


\section{Selection Process}

Crashes involving one vehicle and one pedestrian accounted for 91\% of injuries to pedestrians. Other configurations were excluded from analysis, as lesion mechanisms are too complex to identify when several pedestrians or vehicles are involved. Cases with too much missing data, or in which the pedestrian was unharmed, as well as a few other marginal cases were also excluded.

Hence, with these exclusion criteria, the first study sample comprised 428 fatal and 460 non-fatal crashes (888 observed, 22,375 after weighting). A first analysis was conducted in order to describe the factors associated with fatality for pedestrians hit by any type of vehicle.

A second sample was then selected focusing on crashes involving one pedestrian hit by the front of a passenger car, and comprised 205 fatal and 227 non-fatal crashes $\left(N_{\text {obs }}=432, N_{\text {weighted }}=11,366\right)$. This selection was made because it corresponds to the most frequent crash configuration and because all recent papers dealing with the relationship between pedestrian fatality and impact speed used the same selection.

\section{Speed Assessment}

In a large number of cases, the present data allowed estimation of initial speed (before any crash-related event) and impact speed (defined as a modulus of the vehicle impact speed: i.e., the horizontal component of the speed vector).

Speed estimation was possible in cases where police reports included the following:

- scale drawing of the crash, showing final positions of vehicle and pedestrian, impact points, any traces left by the vehicle, and vehicle direction before the crash;

- description of road conditions, and especially the road surface;

- photographs of the crash scene allowing estimation of impact severity;

- $\quad$ witness statements specifying the sequence of events.

Impact speed was derived from pedestrian throw-distance using various formulae. In the following, D is the distance (in meters) from the point of impact to the final rest location.

- $\quad$ The first formula comes from Toor and Araszewski (Toor and Araszewski 2003): $\mathrm{D}=9.84 \mathrm{D}^{0.57}$ (V in $\mathrm{km} / \mathrm{h}$, D in meters), corresponding to the wrap trajectory model used for car impact. 15th and 85th percentiles can be obtained by applying $\pm 6.5 \mathrm{~km} / \mathrm{h}$.

- The second formula is the positive solution of an equation explained in Depriester (Depriester et al. 2005) and published by Rau: $\mathrm{D}=0.0052 \mathrm{~V}^{2}+0.0783 \mathrm{~V}, \pm 5 \mathrm{~km} / \mathrm{h}$.

- A third model applicable for wrap trajectories (Fugger et al. 2000) is defined as: $V=8.3604 \mathrm{D}^{0.6046}$.

For each crash, all three calculations were made and their results compared. The resulting estimates were usually very close and the average value was adopted. When available, other information, such as skid marks, was used to determine vehicle speed with a different method. In the few cases where a pedestrian was overrun by a car, speed was evaluated from skid marks only. 
Imputation of Impact Speed When Unknown for Selected Crashes (Involving One Pedestrian Hit by the Front of a Passenger Car)

Estimation could be made directly in $43.1 \%$ of crashes but in only $18.1 \%$ of non-fatal crashes (as the information required for estimation was more often missing). When impact speed was unknown, it was imputed from other available information. Multiple imputation was used with a Fully Conditionally Specification (FCS) method (Van Buuren 2007). Missing values were imputed separately for fatal crashes and non-fatal crashes. The imputation models for impact speed included all variables of interest: injury severity, pedestrian age, gender, vehicle mass (19\% unknown), running-over (3\% unknown) and main location of impact on the vehicle (24\% unknown). Some auxiliary variables associated with missing factors or correlated with impact speed were also used: initial speed (40\% unknown), local speed limit, witness testimony regarding speed, type of road, intersection, crash situation, change of direction, time of day, driver's age, driver's alcohol level (12\% unknown), and driver's responsibility. Sixty imputed data sets were thus created, using SAS software version 9.4 (mi procedure). In subsequent analyses, estimates were calculated for each imputed data set, and then combined to assess final estimates and variance matrix (mianalyze procedure). The final variances took account of the average within-imputation and the between-imputation variances, using Rubin's formula (Rubin 1987). Model selection was based on averaged AIC (Akaike Information Criterion), which is the average of AICs for each imputed data set (Consentino and Claeskens 2010).

\section{Choice of Model for the Fatality/Impact-Speed Relation}

All data in the international literature have so far been modeled using a logistic curve, for good theoretical reasons. A logistic curve is symmetrical around point 0.5 on the y-axis: i.e., risk is presumed to rise up to a probability of 0.5 , then decrease toward the asymptote at 1 . However, the energy dissipated at impact is correlated to the square of the speed, suggesting an accelerating risk of death with increasing speed. We therefore implemented a complementary log-log or Gompertz regression. This model is one of the generalized linear model (GLM) family (McCullagh and Nelder 1989) and is similar to a logit model, but with the advantage of not being symmetrical around the inflection point (y-axis 1-1/e). The "complementary log-log" function $g(p)=\log (-\log (1-p))$ is the inverse of the cumulative extreme-value function $F(x)=1-\exp (-\exp (x))$, also called Gompertz distribution.

Concerning vehicle characteristics, bodywork stiffness and height were unknown, and so only the location of the main impact and the vehicle mass were considered. Pedestrians were characterized by age and gender, as morphology was unknown.

Analysis was performed firstly on all vehicles (first sample, above), in order to describe the general context of crashes involving pedestrians, and was secondarily restricted to crashes involving frontal impact (second, selected sample). For the purposes of comparison with other reports, the first model used was logistic regression. The less classical Gompertz regression was then used to plot curves according to speed considered as a continuous variable. The parameters of this model were less easily interpretable than those of the logistic regression, and results were expressed as probability of death, from which relative risks (RR) were derived (Greenland 2004) 


\section{RESULTS}

\section{Factors Associated with Fatality for Pedestrians Hit by Any Type of Vehicle}

Table 1 shows the distribution of pedestrian characteristics (gender, age, alcohol level), crash circumstances (day/night, road category), pedestrian location, type of vehicle, type of impact and running-over, on univariate analysis.

Table 1: Factors associated with fatality for pedestrians hit by any type of vehicle. Proportions, crude odds-ratios and corresponding $95 \%$ C.I. $\left(\mathrm{N}_{\mathrm{obs}}=888, \mathrm{~N}_{\text {weighted }}=22,375\right)$

\begin{tabular}{|c|c|c|c|c|c|c|}
\hline & Factors & Col \% & $\begin{array}{r}\% \\
\text { fatalities } \\
\end{array}$ & $\begin{array}{r}\text { Crude } \\
\text { OR } \\
\end{array}$ & [95\%C.I.] & P value \\
\hline \multirow{2}{*}{ Pedestrian gender } & Female & 50.8 & 1.5 & 1 & & \multirow{2}{*}{0.0010} \\
\hline & Male & 49.2 & 2.3 & 1.62 & {$[1.22 ; 2.15]$} & \\
\hline \multirow{4}{*}{$\begin{array}{l}\text { Pedestrian age } \\
\text { (years) }\end{array}$} & $0-14$ & 20.5 & 0.6 & 0.44 & {$[0.26 ; 0.73]$} & \multirow{4}{*}{$<0.0001$} \\
\hline & $15-59$ & 52.1 & 1.3 & 1 & & \\
\hline & $60-74$ & 17.2 & 2.1 & 1.61 & {$[1.07 ; 2.41]$} & \\
\hline & $>=75$ & 10.3 & 7.4 & 6.09 & {$[4.15 ; 8.94]$} & \\
\hline \multirow{5}{*}{$\begin{array}{l}\text { Pedestrian alcohol } \\
\text { concentration }(\mathrm{g} / \mathrm{l})\end{array}$} & Negative $(<0.5)$ & 38.6 & 2.5 & 1 & & \multirow{5}{*}{$<0.0001$} \\
\hline & $0.5-1.2$ & 0.6 & 6.1 & 2.51 & {$[0.52 ; 12.1]$} & \\
\hline & $1.2-2$ & 0.9 & 10.5 & 4.49 & {$[1.86 ; 10.8]$} & \\
\hline & $>=2$ & 1.1 & 16.0 & 7.34 & {$[2.19 ; 24.6]$} & \\
\hline & None available & 58.8 & 1.0 & 0.4 & {$[0.29 ; 0.54]$} & \\
\hline \multirow{2}{*}{ Day/night } & Day & 76.7 & 1.6 & 1 & & \multirow{2}{*}{$<0.0001$} \\
\hline & Night & 23.3 & 3.0 & 1.98 & {$[1.44 ; 2.72]$} & \\
\hline \multirow{5}{*}{ Type of road } & Highway & 0.9 & 10.3 & 10.1 & [2.54;39.9] & \multirow{5}{*}{$<0.0001$} \\
\hline & Major road & 2.8 & 5.5 & 5.07 & [2.57;9.99] & \\
\hline & Minor road & 15.4 & 4.6 & 4.25 & [3.02;5.99] & \\
\hline & Street & 77.0 & 1.1 & 1 & & \\
\hline & Other & 4.0 & 1.9 & 1.69 & {$[0.77 ; 3.71]$} & \\
\hline \multirow{3}{*}{ Pedestrian location } & On pedestrian crossing & 45.0 & 1.2 & 1 & & \multirow{3}{*}{$<0.0001$} \\
\hline & Outside pedestrian crossing & 45.2 & 2.6 & 2.13 & {$[1.57 ; 2.90]$} & \\
\hline & Off-road & 9.7 & 1.6 & 1.3 & {$[0.77 ; 2.18]$} & \\
\hline \multirow{8}{*}{ Type of vehicle } & Bicycle & 2.4 & 0.4 & 0.23 & {$[0.05 ; 1.06]$} & \multirow{8}{*}{$<0.0001$} \\
\hline & Moped & 6.5 & 0.4 & 0.25 & {$[0.1 ; 0.61]$} & \\
\hline & Motorcycle & 9.4 & 1.0 & 0.63 & {$[0.36 ; 1.1]$} & \\
\hline & Passenger car & 70.4 & 1.6 & 1 & & \\
\hline & Van / utility vehicle & 6.0 & 3.6 & 2.21 & {$[1.32 ; 3.71]$} & \\
\hline & Truck & 1.4 & 18.7 & 13.8 & {$[5.03 ; 37.8]$} & \\
\hline & Bus / coach & 2.5 & 2.8 & 1.75 & {$[0.81 ; 3.81]$} & \\
\hline & Off--road vehicle & 1.4 & 3.6 & 2.26 & {$[0.83 ; 6.17]$} & \\
\hline \multirow{5}{*}{ Type of impact } & Frontal & 71.0 & 2.1 & 1 & & \multirow{5}{*}{0.0729} \\
\hline & Side & 8.6 & 1.1 & 0.55 & {$[0.31 ; 0.97]$} & \\
\hline & Rear & 5.2 & 2.3 & 1.12 & {$[0.62 ; 2.02]$} & \\
\hline & Side-swipe & 4.5 & 1.1 & 0.52 & {$[0.24 ; 1.11]$} & \\
\hline & Other/Unknown & 10.7 & 1.5 & 0.7 & {$[0.44 ; 1.12]$} & \\
\hline \multirow{3}{*}{ Run-over } & No & 91.1 & 1.5 & 1 & & \multirow{3}{*}{$<0.0001$} \\
\hline & Yes & 5.0 & 8.0 & 5.73 & {$[3.53 ; 9.31]$} & \\
\hline & Unknown & 3.9 & 3.4 & 2.34 & {$[1.26 ; 4.34]$} & \\
\hline
\end{tabular}

Pedestrian fatality was significantly higher for males, and also for the elderly, especially those aged 75 and over. Fatality risk appeared to be greater for pedestrians with positive alcohol test $(\geq 0.5 \mathrm{~g} / \mathrm{l})$. However, alcohol level was seldom tested (almost 60\% missing data), despite being mandatory in case of injury, and was not included in the following analyses because of too much missing data, and also to avoid bias as it was probably performed by the police only in specific cases.

Pedestrian fatality and impact speed squared: Cloglog modeling from French national data, accepted author version, 
Pedestrian fatality risk was higher at night, on minor roads, major roads and highways (compared to urban streets), and when crossing the road outside of marked "zebra” crossings.

Fatality was almost 14-fold higher in crashes with trucks, compared to passenger cars, and 2-fold higher with van/utility vehicles or buses/coaches. Running over multiplied the risk of death by 5 , and occurred very often with trucks (48.7\%), quite often with van/utility vehicles (15.5\%) and rarely with cars (4.7\%).

$15.9 \%$ of injured pedestrians were hit by a moped or motorcycle, and $2.4 \%$ by a bicycle, associated with the lowest fatality rates.

Table 1 clearly shows that most crashes involved frontal impact by a passenger car. These crashes are in fact already the object of almost all regulations aiming to reduce crash severity for pedestrians. They are also the crashes for which impact speed can most often be estimated. The following analysis is therefore restricted to one-car/one-pedestrian crashes. The following analysis is therefore restricted to one-car/one-pedestrian crashes in which the pedestrian was hit by the front of a passenger car with impact speed known or imputed by the method described above $\left(\mathrm{N}_{\mathrm{obs}}=432\right.$, $\left.\mathrm{N}_{\text {weighted }}=11,366\right)$.

\section{Risk of Being Killed for a Pedestrian Hit by a Passenger Car According to Impact Speed}

Three models were fitted to estimate the risk of death (logistic against speed, logistic against speed-squared, and cloglog against speed-squared), giving the following estimates for probability of death:

$$
\begin{aligned}
& \widehat{P_{1}}(v)=1 /(1+\exp (7.7265-0.0988 v)) \\
& \widehat{P_{2}}(v)=1 /\left(1+\exp \left(5.8129-0.0011 v^{2}\right)\right) \\
& \widehat{P_{3}}(v)=1-\exp \left(-\exp \left(-5.7389+0.001096 v^{2}\right)\right)
\end{aligned}
$$

Figure 1 plots probability of death according to impact speed for the 3 models.

Figure 1: Risk of death associated with impact speed for a pedestrian hit by a passenger car, according to the three models $\left(\mathrm{N}_{\text {obs }}=432, \mathrm{~N}_{\text {weighted }}=11,366\right)$

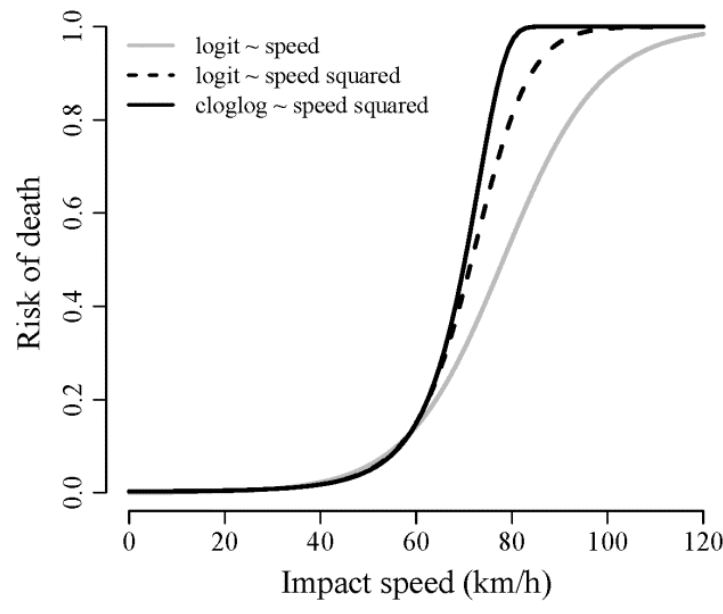

Risk of death according to impact speed was very similar on all 3 models up to $60 \mathrm{~km} / \mathrm{h}$, but then differentiated: respectively, $31 \%, 44 \%$ and $49 \%$ at $70 \mathrm{~km} / \mathrm{h}$, and $54 \%, 81 \%$ and $97 \%$ at $80 \mathrm{~km} / \mathrm{h}$. Model 3 was the best in terms of minimizing information loss (AIC=1560.5 for model 3, 1571.1 for model 2, and 1606.3 for model 1), and was considered the best both statistically and physically (energy striking the pedestrian related to the square of the impact speed). 
To approximate impact energy more closely by taking account of vehicle mass, models 2 and 3 were also tested using $\mathrm{m} . \mathrm{v}^{2}$, but no significant improvement was seen in terms of AIC. Introducing both speed and speedsquared in the cloglog model likewise gave no significant improvement in terms of AIC; the corresponding results are not shown.

Figure 2 shows the curve and confidence interval, calculated following Kutner (Kutner et al. 2004), taking account of weighting.

Figure 2: Probability of death according to impact speed, with $95 \%$ CI $\left(N_{\text {obs }}=432\right.$, $\left.N_{\text {weighted }}=11,366\right)$

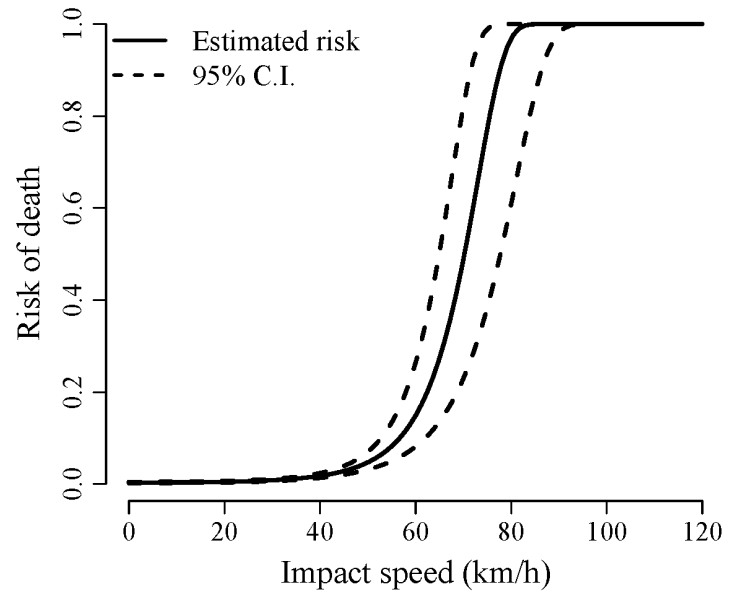

From equation (3), it can be seen that risk of death was low ( 1\%) for $30 \mathrm{~km} / \mathrm{h}$ impacts but, with $30 \mathrm{~km} / \mathrm{h}$ as reference, rose 2-fold at $40 \mathrm{~km} / \mathrm{h}, 6$-fold at $50 \mathrm{~km} / \mathrm{h}, 18$-fold at $60 \mathrm{~km} / \mathrm{h}$ and 59 -fold at $70 \mathrm{~km} / \mathrm{h}$.

A multivariate cloglog model was then fitted, testing the effect of the following factors: pedestrian gender, pedestrian age, vehicle mass, running-over, and main location of impact on the vehicle. When the square of the speed was used, only pedestrian age emerged as a significant co-factor. Equation 4 shows the bivariate cloglog model, taking account of speed and age-group (with 15-59 years of age as reference group):

$$
P(v)=1-\exp \left(-\exp \left(-6.4305+0.00117 v^{2}-0.835 \text { age }_{0-14}+0.600 \text { age }_{60-74}+2.091 \text { age }_{\geq 75}\right)\right)
$$

A possible interaction between age and speed-squared was tested for, but proved non-significant: curves showed increasing values corresponding simply to age-group. Figure 3 plots probability of death against impact speed in the 4 age-groups. 
Figure 3: Probability of death according to impact speed. Model for 4 age categories $\left(\mathrm{N}_{\mathrm{obs}}=432, \mathrm{~N}_{\text {weighted }}=11,366\right)$

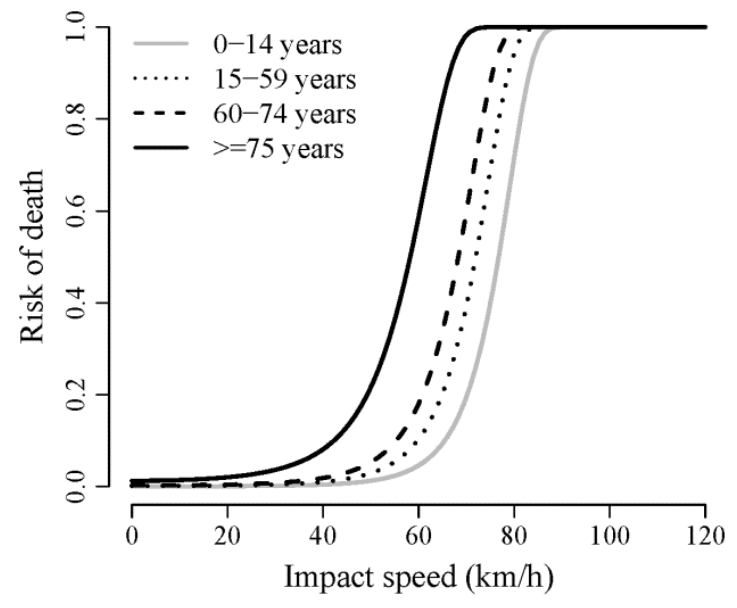

The multivariate model highlighted the frailty of the elderly: 60-74 years, and especially above 75 years. This fragility could be seen as of $30 \mathrm{~km} / \mathrm{h}$ impact speed and up to $50 \mathrm{~km} / \mathrm{h}$, with risk of death increased 2-fold for 60-74 year-olds and 7-fold for over-75 year-olds as compared to 15-59 year-olds. Above $80 \mathrm{~km} / \mathrm{h}$, speed alone was the overwhelming risk factor.

\section{DISCUSSION}

Table 2 compares the present results with those of four recent studies (Davis 2001; Richards 2010; Rosen and Sander 2009; Tefft 2013), all focusing on risk of death in a one-car/one-pedestrian crash in which the pedestrian was injured. 
Table 2: Impact speed $(\mathrm{km} / \mathrm{h})$ at which estimated risk of death reaches 10\%, 25\%, 50\%, 75\% and 90\%: previous studies and current study (with three models)

\begin{tabular}{|c|c|c|c|c|c|c|c|c|}
\hline \multirow[b]{3}{*}{ Study } & \multirow[b]{3}{*}{ Data } & \multirow[b]{3}{*}{$\begin{array}{l}\text { Confounders } \\
\text { adjusted }\end{array}$} & \multirow[b]{3}{*}{ Model } & \multicolumn{5}{|c|}{ Risk of death } \\
\hline & & & & $10 \%$ & $25 \%$ & $50 \%$ & $75 \%$ & $90 \%$ \\
\hline & & & & \multicolumn{5}{|c|}{ Impact speed estimate $(\mathrm{km} / \mathrm{h})$} \\
\hline $\begin{array}{l}\text { Davis } \\
\text { (2001) }\end{array}$ & $\begin{array}{l}\text { United Kingdom, } 1966-1969 \text { and } \\
1973-1979 \text {, data from Ashton ( } N=358, \\
81 \text { fatalities) }\end{array}$ & None & $\begin{array}{l}\text { Logistic regression, } \\
\text { impact speed }\end{array}$ & 53 & 61 & 69 & 79 & 87 \\
\hline $\begin{array}{l}\text { Rosen } \\
(2009)\end{array}$ & $\begin{array}{l}\text { Germany, } 1999-2007, \text { pedestrians } \\
\text { aged } 15 \text { years and over, frontal impact } \\
\text { by passenger car ( } N=490,36 \text { fatalities) }\end{array}$ & Age & $\begin{array}{l}\text { Logistic regression, } \\
\text { impact speed }\end{array}$ & 53 & 66 & 77 & 88 & 100 \\
\hline $\begin{array}{l}\text { Richards } \\
\text { (2010) }\end{array}$ & $\begin{array}{l}\text { United Kingdom, } 2000-2009 \text {, } \\
\text { pedestrians, frontal impact by } \\
\text { passenger car ( } \mathrm{N}=197,66 \text { fatalities) }\end{array}$ & None & $\begin{array}{l}\text { Logistic regression, } \\
\text { impact speed }\end{array}$ & 53 & 61 & 72 & 82 & 100 \\
\hline $\begin{array}{l}\text { Tefft } \\
(2013)\end{array}$ & $\begin{array}{l}\text { United States, 1994-1998, pedestrians } \\
\text { aged } 15 \text { years and over, frontal impact } \\
\text { by passenger car or light truck ( } N=422 \text {, } \\
46 \text { fatalities) }\end{array}$ & $\begin{array}{l}\text { Age, height, } \\
\text { weight, body } \\
\text { mass index, } \\
\text { vehicle type }\end{array}$ & $\begin{array}{l}\text { Logistic regression, } \\
\text { impact speed }\end{array}$ & 43 & 56 & 68 & 79 & 88 \\
\hline \multirow{3}{*}{$\begin{array}{l}\text { Current } \\
\text { study } \\
(2014)\end{array}$} & \multirow{3}{*}{$\begin{array}{l}\text { France 2011, pedestrians, frontal } \\
\text { impact by passenger car, ( } N=432,205 \\
\text { fatalities) }\end{array}$} & \multirow{3}{*}{ None } & $\begin{array}{l}\text { Logistic regression, } \\
\text { impact speed }\end{array}$ & 56 & 67 & 78 & 89 & 100 \\
\hline & & & $\begin{array}{l}\text { Logistic regression, } \\
\text { impact speed-squared }\end{array}$ & 56 & 65 & 72 & 78 & 84 \\
\hline & & & $\begin{array}{l}\text { Cloglog regression, } \\
\text { impact speed-squared }\end{array}$ & 57 & 64 & 70 & 75 & 78 \\
\hline
\end{tabular}

Using the same model, the estimated impact speeds associated with a probability of being killed (Table 3) are very close. The main difference emerges with speed-squared and cloglog modeling, in which the curve can rise more steeply for high impact speeds. This corresponds much more closely to physical reality, and also gives a better fit between observation and estimation.

The cloglog model does not require the curve to be symmetrical around $\mathrm{p}=0.5$, as the logistic model does; this brings the inflection point closer to 1 , thus fitting much better with the use of the square of impact speed. Other models may also position the inflection point in line with the actual data (Goshu and Koya 2013), but we preferred the cloglog model, as it has the advantage of being one of the GLMs with well-known asymptotic properties.

This modeling procedure clearly showed that risk of death approximates 1 for impact speeds above $80 \mathrm{~km} / \mathrm{h}$, which corresponds both to observation and to kinematics. For speeds less than $40 \mathrm{~km} / \mathrm{h}$, as data representative of all crashes resulting in injury were used, the estimated risk of death was fairly low. However, although the curve seems deceptively flat below $50 \mathrm{~km} / \mathrm{h}$, the risk of death in fact doubled when speed rose from 30 to $40 \mathrm{~km} / \mathrm{h}$, and was multiplied by 6 between 30 and $50 \mathrm{~km} / \mathrm{h}$; speed/risk curves are therefore to be interpreted with the greatest caution (Kröyer et al. 2014).

Risk of death was also greater for males on univariate analysis, but not when speed was taken into account. This finding suggests that the elevated risk of death for males, already reported elsewhere (Zhu et al. 2013), is actually due to higher impact speeds due to different crash circumstances. We had expected a negative influence of female gender when speed was taken into account, as other studies suggested that females are less resilient after being hit (Martin and Lenguerrand 2008). 
Coming back to factors associated with fatality for pedestrians hit by any type of vehicle, risk of death was found to be strongly dependent on the type of vehicle hitting the pedestrian. Two-wheel vehicles were involved in a non-negligible number (16\%) of collisions with pedestrians, doubtless due to their particular traffic characteristics (driving between lanes, lower visibility, vehicle dynamics), but with low associated mortality. Vans and other utility vehicles on the other hand were associated with higher mortality than passenger cars. Most belonged to the light truck vehicle (LTV) category, which has been widely studied in relation to injury severity in pedestrian crashes. Desapriya, in a recent meta-analysis (Desapriya et al. 2010), found a 1.54-fold higher risk of pedestrian death $(95 \%$ CI, 1.15;1.93) associated with LTVs than passenger cars, comparable to the present finding of $2.21(1.32 ; 3.71)$.

Crashes in which a pedestrian is hit by a truck have been less widely studied, doubtless due to their relative rarity (1.4\% in the present data-set). However, they are associated with high fatality rates (18\%), for several reasons, which also concern LTVs, although to a much lesser degree: mainly, their vertical front face and high ground clearance, resulting in almost half of cases in running-over, which is always associated with elevated fatality (even when the vehicle is reversing or turning). These findings support the need to improve the front face of trucks, as well as for equipment to improve drivers' detection of pedestrians (Hamacher et al. 2009), so as to reduce the incidence of running-over by modifying pedestrian body kinematics after impact. The same is also true for buses, especially as they are mainly used in urban areas where most pedestrian crashes occur. Runningover is much less frequent with passenger cars.

According to the latest WHO report (WHO 2015), 92 countries (including half of high-income countries) have policies to promote walking and cycling; but, if these policies are not accompanied by other strategies, such as effective speed management and measures to improve pedestrian and cycling safety, they risk actually increasing road traffic injuries. The WHO recently published a road safety manual for decision makers and practitioners (World Health Organization, 2013) which promotes intervention at all levels, such as reducing vehicle speed, separating pedestrians from other road users, increasing pedestrians' conspicuousness, changing pedestrians' and motorists' behavior through education and law enforcement, and improving vehicle design.

\section{Study Limitations}

The study was subject to several limitations. The number of non-fatal injuries included was relatively small. The weighting method used, and validated elsewhere, provided good numbers of estimates, but with consequently wide variance (and thus wide confidence intervals), since based on observed data.

Another limitation comes from the large number of missing values for impact speed, especially for non-fatal crashes. A multiple imputation technique was used, taking account of all available factors associated with the mechanism for which data were missing, including local speed limit and initial speed. This technique generally provides more accurate estimates than a complete-case analysis (Rubin 1987), but can generate larger confidence intervals. This might explain why some variables, such as the specific location of the first impact against the car, were not found to be significant.

Many factors other than impact speed which play a role in the risk of being injured or killed, such as vehicle characteristics, pedestrian anthropometry or second impact consequences, were not considered in this study: 
- Many articles (experimental or real-world crash studies) have been published which show that the risk of severe injury depends on the geometry of the car and on the height of the pedestrian, which determine the wrap-around distance (WAD) and contact points with variable stiffness (del Fueyo et al.). In the present study, pedestrian height was unknown. The main location of the first impact on the vehicle was considered, but found not to be significant when impact speed was taken into account. Regarding car dimensions, many studies have shown that LTVs are associated with greater risk of pedestrian injury or fatality than passenger cars (Desapriya et al. 2010; Roudsari et al. 2005). This result is in concordance with the higher risk associated with vans than passenger cars in the present study (see Table 1). In a previous study (Martin et al. 2011), we reported estimates of the risk of being killed according to four types of car and four types of front profile. Risk of death was shown to be slightly higher for Multi Purpose Vehicles (MPVs) with sloping hoods, although the difference was tiny compared to the impact speed effect.

- Pedestrian weight was unknown, and not considered in the present study. However, mass and speed are considerably greater for the vehicle than the pedestrian: the energy underlying pedestrian speed is overwhelmingly provided by the vehicle and pedestrian mass (and associated factors such as air resistance) can be neglected in the impact speed assessment.

- The distinction in terms of injury between first impact (against the vehicle) and any second impact (against the ground or any other obstacle: e.g., head striking the curb) was impossible to draw from the present data set. However, although in pedestrian crashes the final impact is almost always against the ground, many authors consider that most pedestrian injuries implicate the impact against the vehicle (Crandall et al. 2002; Helmer et al. 2010), as kinetic energy is greatest in the first impact.

Beyond these limitations, collision speed is considered the most important factor by many authors (Hannawald and Kauer 2004; Rosen et al. 2011b). Helmer, in his very comprehensive study (Helmer et al. 2010), fitted a multivariate model to explain the risk of fatality by impact speed, and found that, whether as scale variable, squared or as a part of kinetic energy, impact speed was the strongest single predictive factor. Further research is needed, with more comprehensive data, to estimate the effect of impact speed, adjusted for other important factors such as car front-end characteristics (shape and stiffness of potential contact areas) and pedestrian anthropometry.

\section{CONCLUSION}

For impact speeds less than $60 \mathrm{~km} / \mathrm{h}$, the shape of the curve relating probability of death and impact speed was very similar to those reported in recent rigorous studies. For higher impact speeds, the present model allowed the curve to rise ever more steeply, giving a much better fit with observed data, and a correspondingly better fit with the energy dissipated at impact, which is proportional to the square of the speed.

The present results confirm that, when a pedestrian is struck by a car, impact speed is a major risk factor, thus providing a supplementary argument for strict speed limitation in areas where pedestrians are highly exposed. 
ACKNOWLEDGMENTS

This study was based on data collected as part of the Voiesur project, with funding from the French National Research Agency (ANR). Particular thanks are due to the project leader, Cyril Chauvel (LAB), and the Methodology Officer in charge of determining speeds, Vuthy Phan (Ceesar). The extrapolation method developed by Emmanuelle Amoros (IFSTTAR) was previously made possible using the data of the Rhône RoadAccident Registry, managed by Blandine Gadegbeku, Amina Ndiaye and Bernard Laumon (IFSTTAR). 


\section{REFERENCES}

Alhajyaseen WK, Asano M, Nakamura H. Left-turn gap acceptance models considering pedestrian movement characteristics. Accid Anal Prev. 2013 Jan;50:175-85.

Amoros E, Martin JL, Chiron M, Laumon B. Road crash casualties: characteristics of police injury severity misclassification. J. Trauma. 2007 Feb;62(2):482-90.

Amoros E, Martin JL, Lafont S, Laumon B. Actual incidences of road casualties, and their injury severity, modelled from police and hospital data, France. Eur J Public Health. 2008 Aug;18(4):360-5.

Amoros E, Martin JL, Laumon B. Under-reporting of road crash casualties in France. Accid. Anal. Prev. 2006 Jul;38(4):627-35.

Badea-Romero A, Lenard J. Source of head injury for pedestrians and pedal cyclists: Striking vehicle or road? Accid Anal Prev. 2013 Jan;50:1140-50.

Ballesteros MF, Dischinger PC, Langenberg P. Pedestrian injuries and vehicle type in Maryland, 1995-1999. Accid Anal Prev. 2004 Jan;36(1):73-81.

Consentino F, Claeskens G. Order selection tests with multiply imputed data. Comput. Stat. Data Anal. 2010;54:2284-95.

Crandall JR, Bhalla KS, Madeley N. Designing road vehicles for pedestrian protection. BMJ. 2002;324(7346):1145.

Crocetta G, Piantini S, Pierini M, Simms C. The influence of vehicle front-end design on pedestrian ground impact. Accid. Anal. Prev. 2015;79:56-69.

Davis G. Relating severity of pedestrian injury to impact speed in vehicle-vehicle-pedestrian crashes. Transp Res Rec. 2001;(1773):108-113.

Demetriades D, Murray J, Martin M, Velmahos G, Salim A, Alo K, et al. Pedestrians injured by automobiles: relationship of age to injury type and severity. J Am Coll Surg. 2004 Sep;199(3):382-7.

Depriester J-P, Perrin C, Serre T, Chalandon S. Comparison of several methods for real pedestrian accident reconstruction. Proc 19th Int Tech Conf Enhanc. Saf. Veh. Wash. DC USA [Internet]. 2005 [cited 2017 Mar 9]. Available from: https://www-nrd.nhtsa.dot.gov/Pdf/nrd-01/ESV/esv19/05-0333O.pdf

Desapriya E, Subzwari S, Sasges D, Basic A, Alidina A, Turcotte K, et al. Do light truck vehicles (LTV) impose greater risk of pedestrian injury than passenger cars? A meta-analysis and systematic review. Traffic Inj Prev. 2010;11(1):48-56.

Elvik R, Mysen AB. Incomplete accident reporting; meta-analysis of studies made in 13 countries. Transp Res Rec. 1999;1665:33-40.

del Fueyo RS, Junge M, López-Valdés FJ. Pedestrian Fatal Head Injury Risk as a Function of the Wrap Around Distance (WAD) and the Front Geometry of the Vehicle. [cited 2017 Mar 30]; Available from: https://www.researchgate.net/profile/Mirko_Junge/publication/281685702_Pedestrian_Fatal_Head_Inj ury_Risk_as_a_Function_of_the_Wrap_Around_Distance_WAD_and_the_Front_Geometry_of_the_ Vehicle/links/55f4690508ae1d980394be06.pdf 
Fugger TF, Randles BC, Eubanks JJ. comparison of pedestrian accident reconstruction models to experimental test data for wrap trajectories. London, UK; 2000.

Goshu AT, Koya PR. Derivation of inflection points of nonlinear regression curves - implications to statistics. Am. J. Theor. Appl. Stat. 2013;2(6):268-72.

Greenland S. Model-based estimation of relative risks and other epidemiologic measures in studies of common outcomes and in case-control studies. Am J Epidemiol. 2004;160(4):301-5.

Gupta V, Yang KH. Effect of vehicle front end profiles leading to pedestrian secondary head impact to ground. Stapp Car Crash J. 2013 Nov;57:139-55.

Hamacher M, Fassbender S, Feist F, Gugler J. Modification Of A Truck Front For Improved Kinematics In Run Over Accidents. Proc. 21st Int. Tech. Conf. Enhanc. Saf. Veh. Stuttg. Ger. 2009. p. $15-18$.

Han Y, Yang J, Mizuno K, Matsui Y. Effects of vehicle impact velocity, vehicle front-end shapes on pedestrian injury risk. Traffic Inj Prev. 2012 Sep;13(5):507-18.

Hannawald L, Kauer F. Equal effectiveness study on pedestrian protection. Tech. Univ. Dresd. 2004;

Helmer T, Samaha RR, Scullion P, Ebner A, Kates R. Kinematical, physiological, and vehicle-related influences on pedestrian injury severity in frontal vehicle crashes: multivariate analysis and crossvalidation. Hanover, Germany; 2010. p. 181-98.

Henary BY, Crandall J, Bhalla K, Mock CN, Roudsari BS. Child and adult pedestrian impact: the influence of vehicle type on injury severity. Annu Proc Assoc Adv Automot Med. 2003;47:105-26.

Henary BY, Ivarsson J, Crandall JR. The influence of age on the morbidity and mortality of pedestrian victims. Traffic Inj Prev. 2006 Jun;7(2):182-90.

Hook EB, Regal RR. Capture-recapture methods in epidemiology: methods and limitations. Epidemiol Rev. 1995;17:243-64.

Kim J-K, Ulfarsson GF, Shankar VN, Kim S. Age and pedestrian injury severity in motor-vehicle crashes: A heteroskedastic logit analysis. Accid. Anal. Prev. 2008;40(5).

Kröyer HR, Jonsson T, Várhelyi A. Relative fatality risk curve to describe the effect of change in the impact speed on fatality risk of pedestrians struck by a motor vehicle. Accid. Anal. Prev. 2014;62:143-152.

Kutner M, Nachtsheim C, Neter J, Li W. Applied Linear Statistical Models. New York.: McGrawHill/Irwin; 2004.

Mallory A, Fredriksson R, Rosén E, Donnelly B. Pedestrian injuries by source: serious and disabling injuries in US and European cases. Ann. Adv. Automot. Med. Sci. Conf. Association for the Advancement of Automotive Medicine; 2012. p. 13.

Martin JL, Lardy A, Laumon B. Pedestrian Injury Patterns According to Car and Casualty Characteristics in France. 55th Ann. Adv. Automot. Med. AAAM Annu. Conf. Paris: Association for the Advancement of Automotive Medicine; 2011.

Martin JL, Lenguerrand E. A population based estimation of the driver protection provided by passenger cars: France 1996-2005. Accid. Anal. Prev. 2008;40:1811-1821. 
McCullagh P, Nelder JA. Generalized linear models. 2nd ed. Chapman \& Hall; 1989.

Okamoto Y, Sugimoto T, Enomoto K, Kikuchi J. Pedestrian head impact conditions depending on the vehicle front shape and its construction--full model simulation. Traffic Inj Prev. 2003 Mar;4(1):74-82.

ONISR. La sécurité routière en France, Bilan de l'année 2011, La Documentation Française, Paris, France [Internet]. 2014. Available from: http://www.securite-routiere.gouv.fr/la-securite-routiere/lobservatoire-national-interministeriel-de-la-securite-routiere/accidentalite-routiere

Otte D. Severity and mechanism of head impacts in car to pedestrian accidents. Proc. Int. Res. Counc. Biomech. Inj. Conf. International Research Council on Biomechanics of Injury; 1999. p. 329-341.

Pulugurtha SS, Sambhara VR. Pedestrian crash estimation models for signalized intersections. Accid Anal Prev. 2011 Jan;43(1):439-46.

Richards D. Relationship between Speed and Risk of Fatal Injury: Pedestrians and Car Occupants [Internet]. 2010.2 Available from: http://webarchive.nationalarchives.gov.uk/20121105134522/http://assets.dft.gov.uk/publications/pgrroadsafety-research-rsrr-theme5-researchreport16-pdf/rswp116.pdf

Richards D, Carroll J. Relationship between types of head injury and age of pedestrian. Accid Anal Prev. 2012 Jul;47:16-23.

Richmond SA, Rothman L, Buliung R, Schwartz N, Larsen K, Howard A. Exploring the impact of a dedicated streetcar right-of-way on pedestrian motor vehicle collisions: A quasi experimental design. Accid Anal Prev. 2014a Jun 17;71C:222-7.

Richmond SA, Willan AR, Rothman L, Camden A, Buliung R, Macarthur C, et al. The impact of pedestrian countdown signals on pedestrian-motor vehicle collisions: a reanalysis of data from a quasiexperimental study. Inj Prev. 2014b Jun;20(3):155-8.

Rosen E, Sander U. Pedestrian fatality risk as a function of car impact speed. Accid Anal Prev. 2009 May;41(3):536-42.

Rosen E, Stigson H, Sander U. Literature review of pedestrian fatality risk as a function of car impact speed. Accid Anal Prev. 2011a Jan;43(1):25-33.

Rosen E, Stigson H, Sander U. Literature review of pedestrian fatality risk as a function of car impact speed. Accid Anal Prev. 2011b Jan;43(1):25-33.

Roudsari BS, Mock CN, Kaufman R. An Evaluation of the Association Between Vehicle Type and the Source and Severity of Pedestrian Injuries. Traffic Inj. Prev. 2005 Jun;6(2):185-92.

Roudsari BS, Mock CN, Kaufman R, Grossman D, Henary BY, Crandall J. Pedestrian crashes: higher injury severity and mortality rate for light truck vehicles compared with passenger vehicles. Inj Prev. 2004 Jun;10(3):154-8.

Rubin D. Multiple Imputation for Nonresponse in Surveys. New York: John Wiley and Sons; 1987.

Tefft BC. Impact speed and a pedestrian's risk of severe injury or death. Accid Anal Prev. 2013 Jan;50:871-8.

Toor A, Araszewski M. Theoretical vs. Empirical Solutions for Vehicle/Pedestrian Collisions. SAE Tech. Pap. [Internet]. SAE International; 2003. Available from: http://dx.doi.org/10.4271/2003-010883 
Van Buuren S. multiple imputation of discrete and continuous data by fully conditional specification. Stat. Methods Med. Res. 2007;16(219-242).

Watanabe R, Katsuhara T, Miyazaki H, Kitagawa Y, Yasuki T. Research of the relationship of pedestrian injury to collision speed, car-type, impact location and pedestrian sizes using human FE model (THUMS Version 4). Stapp Car Crash J. 2012 Oct;56:269-321.

WHO. WHO Global Status Report on Road Safety [Internet]. World Health Organisation; 2015 p. 12. Available from: http://www.who.int/violence_injury_prevention/road_safety_status/2015/en/

World Health Organization, FIA Foundation for the Automobile and Society, Global Road Safety Partnership, World Bank. Pedestrian safety: a road safety manual for decision-makers and practitioners [Internet]. Geneva: World Health Organization; 2013 [cited 2017 Apr 3]. Available from: http://www.grsproadsafety.org/sites/grsp.drupalgardens.com/files/201304/PedestrianSafety_eng.pdf

Zegeer CV, Bushell M. Pedestrian crash trends and potential countermeasures from around the world. Accid Anal Prev. 2012 Jan;44(1):3-11.

Zhu M, Zhao S, Coben JH, Smith GS. Why more male pedestrians die in vehicle-pedestrian collisions than female pedestrians: a decompositional analysis. Inj. Prev. 2013;19(4):227-231. 